\title{
MENSAGENS/CARTAS TROCADAS SOBRE TEMPOS DE ERRÂNCIA EM TEMPOS DE PANDEMIA corpos em desaparição
}

\author{
Dirce Helena de Carvalho ${ }^{1}$ \\ Narciso Telles ${ }^{2}$ \\ com a colaboração de Maria Marques ${ }^{3}$
}

\begin{abstract}
RESUMO
O presente ensaio se propõe a fazer uma reflexão sobre o processo de criação do espetáculo Tempos de Errância com texto de Rosyane Trotta, direção de Dirce Helena Carvalho e atuações de Narciso Telles e Guilherme Conrado. A obra trata de desaparições forçadas na América Latina contemporânea. A importância desta reflexão acerca da ausência de corpos, bem como dos disparadores que nortearam o processo de criação atoral, serão discutidos no decorrer do texto, no qual apresentaremos o caminho percorrido na criação de Tempos de Errância. Por conseguinte, não há como deixar de estabelecer relações das ausências de corpos na América Latina com o momento em que estamos sendo afligidos pela pandemia da COVID-19, com pessoas que desaparecem de nossas vidas. Deste modo, tomamos a liberdade em apresentar uma discussão pautada na ausência de corpos no espetáculo Tempos de Errância e, ao mesmo tempo, expandir minimamente tal discussão ao agregar questões das ausências presentes neste momento pandêmico.
\end{abstract}

PALAVRAS-CHAVE: Cena Contemporânea; Atoralidade; Corpo; Desaparição Forçada

\footnotetext{
1 Atriz, Diretora, Pesquisadora, doutorado em Educação pela Universidade de São Paulo. Atualmente é Professora do Curso de Graduação (licenciatura e bacharelado), do Programa Mestrado Profissional em Artes - Porfartes e do Programa de Pós-Graduação em Artes Cênicas - PPGAC da Universidade Federal de Uberlândia. Líder e pesquisadora do Grupo GEAC - Grupo de estudos de formação e criação em Artes Cênicas. Sua pesquisa enfoca as questões da atuação/atoralidades, corpo-voz e pedagogia teatral.

2 Teatreiro, ator e diretor. Pós-Doutor em Teatro (UDESC, 2012), (UAM/Universidad Castilla de la Macha, 2017 - Programa Estágio Sênior/CAPES). É professor do Curso de Teatro (licenciatura e bacharelado), do Programa de Pós-Graduação em Artes Cênicas e Mestrado Profissional em Artes na Universidade Federal de Uberlândia (UFU) e colaborador no Programa de Pós-Graduação em Educação/UFU e no PPGAC/UFMA. Pesquisador do CNPq e do GEAC/UFU. Membro do Núcleo 2 Coletivo de Teatro Uberlândia - MG.

3 Docente Titular e Pesquisadora do Curso de Teatro da Universidade Federal de Uberlândia.
} 


\title{
MENSAJES/CARTAS INTERCAMBIADAS SOBRE TEMPOS DE ERRÂNCIA EN TIEMPOS DE PANDEMIA cuerpos desaparecidos
}

\begin{abstract}
RESUMEN
Este ensayo propone realizar una conversación reflexiva sobre el proceso de creación del espectáculo Tempos de Errância con texto de Rosyane Trotta, dirigida por Dirce Helena Carvalho y actuaciones de Narciso Telles y Guilherme Conrado. El trabajo trata sobre desapariciones forzadas en América Latina contemporánea. La importancia de esta reflexión sobre la ausencia de cuerpos, así como los desencadenantes que guiaron el proceso de creación de actores, se discutirá a lo largo del texto buscando presentar el camino tomado en la creación de Tempos de Errância. En consecuencia, no hay forma de no establecer relaciones entre la ausencia de cuerpos en América Latina y el momento en que estamos siendo afectados por la pandemia de COVID-19, con personas que desaparecen de nuestras vidas. De esta manera, nos tomamos la libertad de presentar una discusión basada en la ausencia de cuerpos en el espectáculo Tempos de Errância y, al mismo tiempo, expandimos mínimamente esta discusión agregando temas de ausencias presentes en este momento pandémico.
\end{abstract}

PALABRAS CLAVE: Escena Contemporánea; Actoralidad; Cuerpo; Desaparición Forzada

\section{MESSAGES/LETTERS EXCHANGED ABOUT TEMPOS DE ERRÂNCIA IN TIMES OF PANDEMIC bodies disappearing}

\begin{abstract}
This essay proposes to make a reflective conversation about the process of creating the play Tempos de Errância with text by Rosyane Trotta, directed by Dirce Helena Carvalho and performances by Narciso Telles and Guilherme Conrado. The work deals with forced disappearances in contemporary Latin America. The importance of this reflection on the absence of bodies, as well as the triggers that guided the process of actor creation, will be discussed throughout the text seeking to present the path taken in the creation of Tempos de Errância. Consequently, there is no way to fail to establish relationships between the absence of bodies in Latin America and the time when we are being afflicted by the pandemic of COVID-19, with people who disappear from our lives. In this way, we take the liberty of presenting a discussion based on the absence of bodies in the play Tempos de Errância and, at the same time, minimally expand this discussion by adding issues of absences present in this pandemic moment.

KEYWORDS: Contemporary Scene; Actorality; Body; Forced Disappearance
\end{abstract}




\section{9 de maio de $2020^{4}$}

Pessoas infectadas no Brasil pela COVID-19: 22.013 (vinte e duas mil) Mortes no país: 965 (novecentos e sessenta e cinco)

\section{[Dirce Helena]}

A reflexão a ser feita nasce de um desejo junto ao artistapesquisador Narciso Telles, desde o momento em que iniciamos o processo de criação do espetáculo Tempos de Errância, em janeiro de 2019. Ontem, oito de maio de 2020, Narciso me fez um convite enviado pelo WhatsApp para escrevermos um ensaio sobre Tempos de Errância a ser publicado neste Dossiê da revista Rascunhos: Caminhos para a pesquisa em Artes Cênicas do GEAC/UFU, organizado por Eduardo De Paula ${ }^{5}$, somando-se às contribuições da docente e pesquisadora Maria Marques na formulação de questões provocadoras agregadas ao texto deste ensaio.

Pela natureza deste texto faremos uso de imagens, de memórias, de imagens, de escritas no decorrer do processo de criação, de reprodução de áudios via WhatsApp trocados com Narciso Telles, de entrevistas concedidas nas mídias sociais, de pequenos textos já escritos sobre as errâncias e de autores com os quais estabeleceremos diálogos no decorrer de nossa escrita. Tais disparadores constituíram-se, pois, em desafio para a escrita deste ensaio que debruçar-se-á sobre um processo de criação teatral já estreado no Teatro CEU Shopping Park, em 14 de novembro de 2019, cuja temporada foi até 17 de novembro de 2019, na cidade de Uberlândia - MG, e também da apresentação na sala Ana Carneiro do Bloco 3M, quando integramos a programação da Semana de Abertura do Semestre de 2020.1 do Curso de Teatro da Universidade Federal de Uberlândia.

Assim que recebi o convite de Narciso, imediatamente me veio à memória os dibujos de Goya em minha visita à exposição nos dias 03 e 04 de

\footnotetext{
${ }^{4}$ Informação obtida no site: https://agenciabrasil.ebc.com.br/saude/noticia/2020-05/covid-19pais-registra-965-mortes-nas-ultimas-24-horas. Acesso em 09 de maio de 2020.

5 Artista/Pesquisador e Professor da graduação (licenciatura e bacharelado) e do Programa de Pós-Graduação em Artes Cênicas - PPGAC do Curso de Teatro da Universidade Federal de Uberlândia.
} 
fevereiro de 2020, intitulada Goya Dibujos - Solo la voluntad me sobra, no Museu Nacional do Prado em Madri/Espanha, realizada no período de 20 de novembro de 2019 a 16 de fevereiro de 2020.

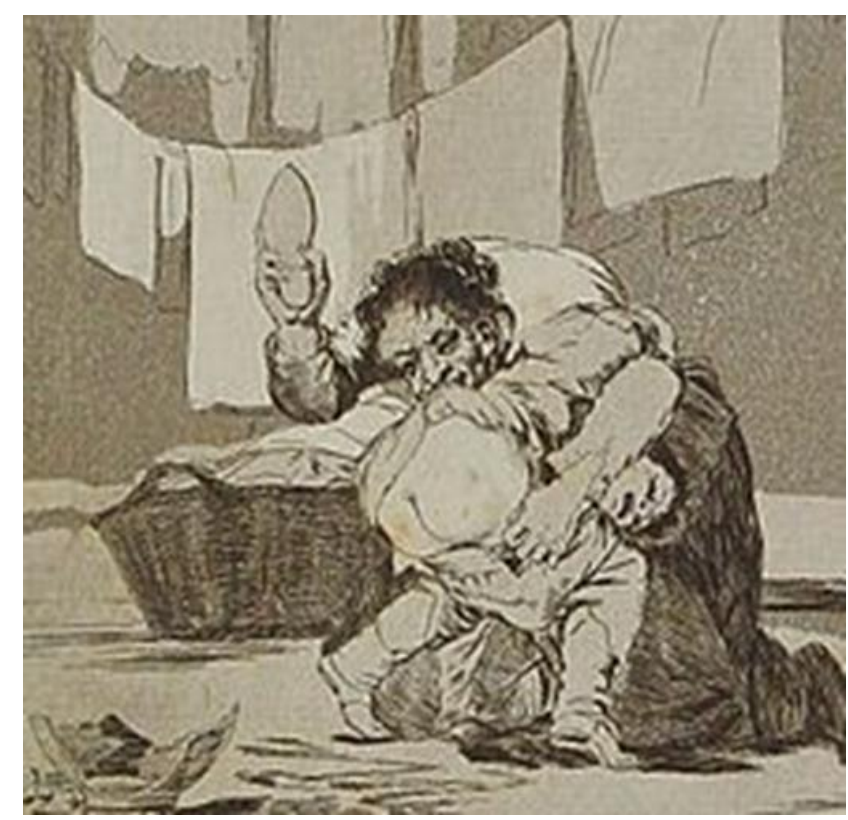

Quebrou o cântaro. (Pormenor) ${ }^{6}$

Exposição Solo la voluntad me sobra - Museo Del Prado/2020

Verdadeiras obras de arte derivadas do aguçamento e da percepção de mundo do artista espanhol, os pequenos dibujos, no tamanho dos antigos cartões postais, acompanhados de pequenas narrativas, compondo uma cronologia temática, muitas delas sobre violência, tais como, as violências da natureza humana, das irracionalidades que se perpetuam em violências, horrores que destroem vidas; violência das torturas; violência dos homens contra as mulheres; a mulher concebida como objeto, dentre outros, todo esse material integra os cuadernos de dibujos do artista, Cuaderno Italiano, Cuaderno de Sanlúcar, Cuaderno de Madrid, Cuaderno de viejas y brujas, dentre outros. Temas extremamente atuais chamam a atenção logo a partir do título da exposição que se remete a uma carta do artista para Joaquín Maria Ferrer, político e editor de livros da época. Em um dos trechos, o artista diz "Agradézcame usted mucho estas malas letras, porque ni vista, ni

\footnotetext{
${ }^{6}$ A imagem integra as oitenta estampas dos Caprichos - assuntos caprichosos. "Em 1799, foi posta à venda uma coleção de oitenta estampas de assuntos caprichosos gravadas à águaforte pelo pintor Francisco de Goya, que contava 53 anos de idade. Nestas gravuras, mediante o ridículo, a extravagância e a fantasia, censurava erros e vícios da Espanha da época". In: https://pt.wikipedia.org/wiki/Los caprichos. Acesso em 18 de junho de 2020.
} 
pulso, ni pluma, ni tinteiro, todo me falta, y solo la voluntad me sobra"7 Fiquei extremamente impactada com a exposição e, principalmente, com o título Solo la voluntad me sobra.

Neste período em que me encontrava em Madrid, a COVID-19 já se manifestava na Espanha e muito pouco se falava sobre este inimigo invisível. Algumas notícias que recebíamos sobre a pandemia estavam bem longe de nós, literalmente lá na China. No entanto, neste momento estamos sendo acometidos pela pandemia COVID-19, com uma subnotificação do Ministério da Saúde de vinte e quatro de maio de dois mil e vinte, das últimas vinte e quatro horas, perfazendo um total de 965 (novecentas e sessenta e cinco) novas mortes por COVID-19, totalizando 22.013 (vinte e dois mil e treze infectados) no país, de acordo com o boletim diário do Ministério da Saúde.

Falar de um passado próximo, ou seja, do processo de criação em Tempos de Errância, forçosamente faz-se necessário refletir sobre os "novos modos" de teatro que estão surgindo nas mídias sociais e dos que surgirão no pós-pandemia e, enquanto artista e pesquisadora, não posso me eximir em expressar minimamente minhas incertezas e indagações em tempos em que somos assolados pela de pandemia do COVID-19. É impossível apartar-me das questões trazidas pela pandemia e, isolada em meu apartamento, longe das pessoas de minha convivência, com muitas inseguranças, constato que a frase de Francisco Goya Solo la voluntad me sobra, ressoa fortemente em mim. Assemelha-se, portanto, ao que sinto neste momento em meio a pandemia do COVID-19, recolhida em minha casa, sem contato com a minha família, amigos, afastada do meu trabalho, em interrupção forçada das apresentações que estavam programadas para Tempos de Errância. O que me resta, entre outras, é a vontade de refletir sobre o processo de criação deste espetáculo, cuja temática apresenta a ausência de presença, uma vez que trata do desaparecimento de corpos na América Latina, em um vilarejo na Colômbia.

7 (GOYA, catálogo da exposição, 2019). 
Recorro a Jorge Dubatti, um dos mais renomados pensadores do teatro da América Latina, mais especificamente à obra Teatro dos Mortos: uma introdução à filosofia teatral, (2016). O autor traz reflexões singulares sobre o "teatro como acontecimento", discutindo sobre os paradigmas da cultura teatral o autor enfatiza o teatro tecnovial e o teatro aurático, presencial, onde há o encontro de fisicidades, corpos de atores e espectadores (DUBATTI, 2016).

Ao definir etimologicamente a palavra teatro, Dubatti (2016), considera-a do mesmo modo que "mirante", "observatório" e não apenas sob o aspecto da visão, mas sobretudo de experiências de convivência "Está-se no teatro com todos os sentidos e cada uma das capacidades humanas. O teatro é um lugar para viver, segundo o conceito de convívio e cultura vivente, e a poiesis não é apenas olhada ou observada, mas vivida" (DUBATTI, 2016, p. $12)$.

Estamos diante de um "novo" paradigma e a partir da reflexão apresentada por Jorge Dubatti, lançamos algumas questões: Como serão os compartilhamentos dos "acontecimentos teatrais"? Serão um híbrido entre o presencial e o semipresencial? Será possível uma nova arquitetura teatral que possibilite o convívio do corpo-presença-sentido? O acontecimento teatral poderá ser compartilhado com inúmeros espectadores aos quais estamos acostumados? Embora não saibamos como se fará o "teatro como acontecimento" no pós-pandemia, nasce um novo paradigma a ser enfrentado.

Inúmeras as questões que poderão ser alçadas para refletirmos acerca do teatro pós-pandêmico, no entanto, nos propusemos a falar do processo de criação em Tempos de Errância, experiências compartilhadas com o espectador e a pergunta que não quer calar: é possível nos apartarmos desta pandemia ao lançarmos o nosso olhar para as errâncias?

Deste modo, a reflexão sobre o processo de criação de Tempos de Errância, atrela-se diretamente ao momento de um passado próximo e do tempo presente em que convivemos com esta pandemia. Outras questões/frições relacionadas ao teatro no pós-pandemia irão surgir no 
decorrer desta escrita que, certamente, se apresentarão de forma fragmentada, truncada, apresentada em partes, com reflexões que remetem ao passado próximo do processo de criação de Tempos de Errância, alternando-se ao pré e ao pós-pandemia, expressas em esboços, rabiscos, garatujas, em uma tentativa de reter o processo de criação já consolidado e de reflexões de possíveis "novos modos" do fazer teatral em tempos que virão...

\section{Reprodução do áudio 1 \\ Enviado para Narciso Telles - via WhatsApp, em 08 de maio de 2020.}

Narciso, gostei muito da ideia de falarmos sobre o processo de criação em Tempos de Errância, acho que as provocações de Maria Marques são muito bem-vindas e nos ajudarão a fazer uma reflexão acerca das errâncias com ênfase nas questões processuais de nossa criação. O que me moveu, o que te moveu, o que nos inquietou, quais foram os anteparos desenvolvidos no decorrer do processo de criação, por fim, me advêm inúmeras questões neste momento. O que ocorria em nossos encontros e como fomos trabalhando com as memórias, sensações, motivações, impressões e sensações advindas de nossos encontros para a composição do espetáculo? Estes momentos de abalos exigem de nós, artistas, abandonarmos nossa zona de conforto convocando-nos a reflexão, a nos manifestarmos, clamarmos sobre os acometimentos de nossas realidades. E, no caso da pandemia, não é um acontecimento territorial, mas uma doença que se expande para todo o globo terrestre. E ao falar sobre as errâncias, não há a possibilidade de não traçar um paralelo das errâncias com a pandemia. CORPOS... VIDAS que se findam, e em ambas as situações não há o RITUAL da morte, tão presente em nossas culturas. Os corpos das pessoas acometidas pela pandemia assemelham-se aos corpos dos desaparecidos em Tempos de Errância, uma vez que não se faz possível realizar o ritual de passagem. Como ficam os seus familiares? A dor da perda e a dor de não se despedir. Muito triste. A eterna presença da ausência...

Os ensaios iniciaram-se em janeiro de 2019, quando de uma imersão com Rosyane Trotta e os atores do Coletivo de Teatro Núcleo 2. Inicialmente, a equipe estava trabalhando e o texto da primeira Errância, Voz I, estava quase finalizado pela dramaturga. Foi o meu primeiro contato com o coletivo e sabia quase nada sobre a montagem, pois Narciso conversou 
rapidamente comigo convidando-me para dirigir o trabalho. Neste momento, silenciei-me para poder adentrar o universo das errâncias e presenciar as improvisações com Narciso Telles e Guilherme Conrado, já imersos na busca da ambiência que se apresenta na Voz I. Imediatamente, dado ao tema e a dramaturgia que se apresentavam, percebi que se tratava de "personagemtestemunha-de-si-mesmo e da ação na qual está inserido" (SARRAZAC, 2013, p.18), e que a encenação se daria igualmente a um manifesto sobre as ausências presentes.

[Maria Marques]

Sabendo que o processo de criação do espetáculo Errância nasce de uma investigação tanto de tema como a criação do processo atoral, vocês poderiam descrever a metodologia de trabalho adotada por vocês, destacando o tema?

[Narciso Telles]

Tempos de Errância tem como primeiro disparador a crônica "Remanso de Beltran", de Juan Miguel Alvarez sobre as desaparições forçadas na Colômbia. A este material foram agregando-se outras narrativas colombianas e brasileiras sobre a mesma temática. Convidei a dramaturga Rosyane Trotta para juntos iniciarmos, em encontros virtuais, um primeiro tratamento dramatúrgico, antes de iniciarmos os ensaios. Uma primeira questão mobilizadora era como representar as ausências?

[Dirce Helena]

A escrita do texto de Rosyane Trota confronta as violências na América Latina apresenta um cenário de um vilarejo abandonado onde não há a possibilidade de mudanças. Composto em três tempos, quais sejam: Voz I, Voz II e Voz III, que embora tratem do mesmo tema, podem ser apresentadas separadamente; situam as escolhas éticas e estéticas diante do tema da desaparição forçada na América Latina. Assim, a consideração do texto enquanto matéria cênica e a ênfase na temática das violências da 
América Latina constituíram as bases da encenação em Tempos de Errância.

O processo da direção teatral constituiu-se, portanto a partir do texto de Rosyane Trotta e dos materiais que fomos investigando no decorrer do processo de criação, buscando congregar a multiplicidade de vozes advindas dos participantes deste coletivo, o que configura o espetáculo em um trabalho polifônico. Tornou-se, fundamental a concretude de um espaço de mediação entre a matéria cênica e a performance dos atores através de uma "escuta" sensível da direção para adentrar o universo das errâncias.

O fenômeno artístico na cena contemporânea reconstrói o texto teatral, articulando a criação simultânea de todos os elementos constituídos no decorrer do processo de criação. Tais articulações estão comumente inscritas em processos de criação onde há a presença do dramaturgista/dramaturg no acompanhamento do processo, com a função de agrupar e selecionar materiais cênicos apresentados no decorrer do processo de criação e, principalmente, na chancela de todas as vozes do coletivo.

Entender cada uma das vozes para buscar o tratamento cênico a ser dado, passou a ser fundamental para as investigações da encenação junto aos atores. Incialmente, um rol de questões se nos apresentava, a saber, Quem é este homem, este ser-vivente que faz a recolha de corpos? De onde são trazidos? Por que ele tira as pessoas mortas do rio? O que ele faz com os corpos? Qual a relação, ou ainda, qual o significado que os corpos tem para ele? Como entender este lugar abandonado, praticamente sem vida, um pequeno povoado abandonado da Colômbia? O que teria ocorrido neste lugar tão assombrado pela morte recebendo corpos em decomposição? De quem são estes corpos?

[Narciso Telles]

Amparados em minhas conversas e estudos com Ileana Diéguez (México) sobre as teatralidades da dor e com José Antônio Sanchez (Espanha) sobre ética e representação, iniciei uma primeira série de improvisações em sala de trabalho junto com Guilherme Conrado. Já sabia 
que o espetáculo seria polifônico e com um desenho de atuação que vai do 'personagem' ao ator em jogo. Da representação à "presentação". Nas primeiras improvisações começamos a desenhar a Errância I, na qual o personagem 'Recolhedor de Corpos' narra seu dia a dia e sua relação com os cadáveres. Uma primeira aproximação foi a partir da relação recolhedorurubu. Buscando a criação de um corpo afetado/cênico, tive como caminho a pesquisa do urubu como um corpo-base. Assim passei dias acompanhando, fotografando e vendo vídeos sobre os urubus em seu habitat. Aos poucos fui assimilando corporalmente aspectos do animal e humanizando-o. Nesse momento já tínhamos a parceria de Dirce Helena Carvalho na direção.

\section{[Dirce Helena]}

A direção priorizou as investigações atorais, abalizadas a partir da diversidade de materialidades cênicas (palavra, espaço, imagens, gestos, sons, luz, figurino). Considerando a complexidade e os dispositivos da encenação contemporânea, inferimos que os atores, sujeitos em devir, instaurassem novas arquiteturas cênicas no decorrer do processo criativo, irrompendo nos hibridismos e contaminações, onde as representações e representatividades, a saber, o fictício e o real, se inserissem no discurso teatral, sendo possível representar a cena e a si mesmo.

Nesse sentido, os procedimentos utilizados em suas relações com as situações apresentadas nas três errâncias, possibilitou verificar o transbordamento de questões da cena contemporânea abalizadas pela tríade personagem-ator-testemunha. Ao esquadrinharmos estas experiências a partir da ênfase nas atoralidades, por nós estabelecidas, consideramos as contaminações e hibridações deles entre si, uma vez que a cena contemporânea se distingue pela dissolução de limites. Ainda assim, buscamos assegurar sistematicidade e criticidade em nossas práticas, buscando coerência nos critérios investigativos. 
[Maria Marques]

A presença do personagem que ilumina vários quadros das cenas Guilherme Conrado - ficou, para mim um ponto fora do tecido dramatúrgico (o que já exige muito do espectador). Ora o via como um alter-ego do protagonista, ora como um jornalista, ora como um ente querido do protagonista (eles se abraçam várias vezes) ou até um possível morto... Enfim, pensei em várias possibilidades de jogo.

\section{[Narciso Telles]}

Gosto de pensar a presença de Guilherme Conrado, mas como um modo de existência cênico do que um personagem. Todas essas observações cabem numa análise das funções que sua atuação ocupa na estrutura dramatúrgica, porém, mais que isso é sua presença em cena estabelece a clara perspectiva que estamos vivendo uma outra realidade, não análoga a uma realidade de referência, mas a possibilidade de como o teatro instaura um outro espaço-tempo durante sua realização. Seguindo Jean Luc Nancy 'o corpo enuncia e ele se enuncia, impedindo-se como um enunciado (e como enunciação)' (p.81) E é nesse sentido que percebo a potência na relação com atuação de Guilherme Conrado, como um corpo que se enuncia em cada Errância e assim compõe a cena na relação que temos e que vamos construindo ao longo do espetáculo. Na Errância I ele fratura uma certa ideia de cena fechada na ficção, no qual eu estou submetido no registro de um personagem.

As ausências aparecem na Errância II no que permanece, as roupas e os sapatos. Nesta a pergunta disparadora foi: como dar presença às ausências? As obras surgidas a partir das teatralidades da dor, termo cunhado por Ileana Dieguez, sempre encontram nessa questão uma potência criativa. A opção que escolhemos foi 'dar vida' às roupas, contar suas histórias. Inventamos essa errância cruzando as vozes/narrativas com técnicas de teatro de animação, atuamos como atores-manipuladores aparentes e em certo sentido cumplices dessas histórias, somando-se às narrativas de vozes femininas em off criadas pelas atrizes Dirce Helena 
Carvalho e Brenda Oliveira. Na sala de trabalho, com as roupas dispersas no chão e a orientação técnica em teatro de animação de Mário Piragibe, fomos tecendo suas trajetórias, confrontando-as em relação aos nossos corpos. No processo técnico-inventivo fomos apurando as dinâmicas, os modos de operação de cada roupa e compreendendo em experiência qual a história escondida em cada uma delas que iam se revelando a cada ensaio. Eduardo Pavlovsky, ator e dramaturgo argentino, diz que atuar é um modo de viver nossa condição humana em um ato extremo. Nesse espetáculo, vivo isso diferentemente em cada uma das três errâncias, para ao fim recolher meus cadáveres e me preparar para a próxima função.

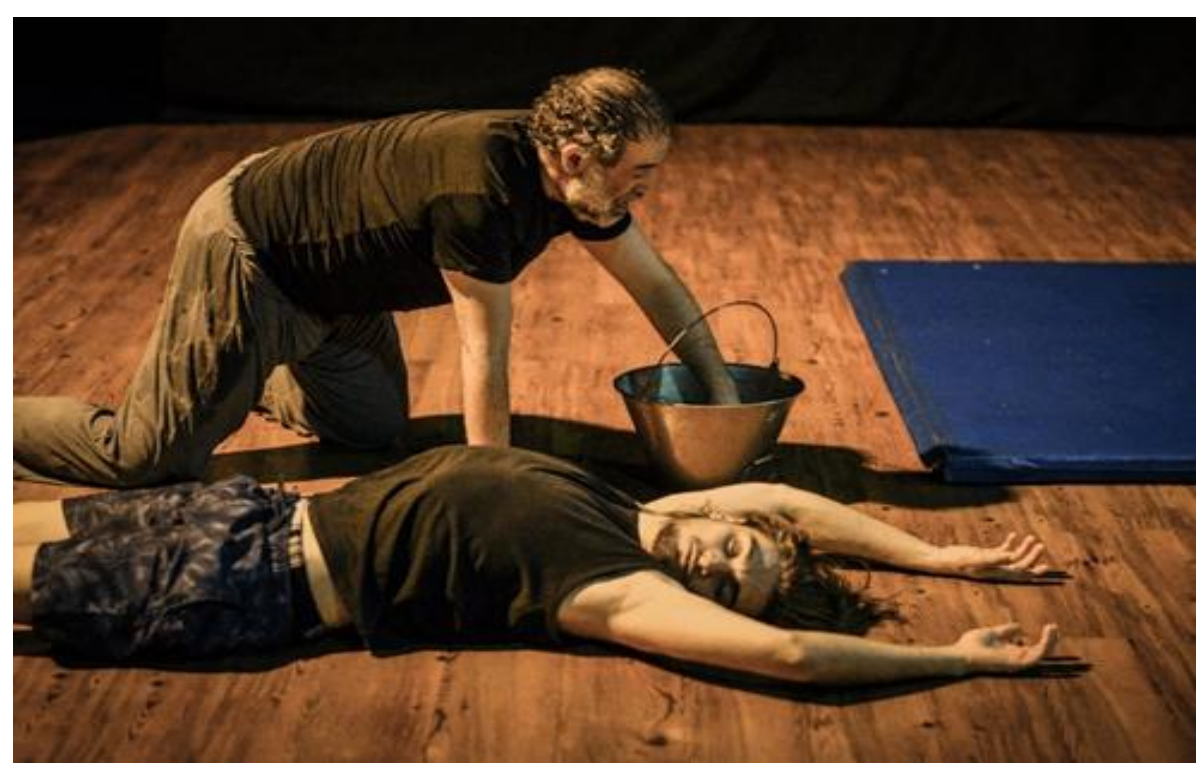

Foto do acervo. Narciso Telles e Guilherme Conrado.

Foto: Moana Marques (@ladymoah)

Local: Sala Ana Carneiro - Bloco 3M - Campus Santa Mônica/UFU.

[Dirce Helena]

A foto acima foi tirada nos ensaios iniciais no momento em que investigávamos o lugar onde se passa a história deste ser-vivente que recolhe corpos de pessoas desaparecidas, Narciso Telles com um balde de água nas improvisações iniciais, trazendo muita água para o espaço da cena, numa tentativa de entrarmos em contato com o lugar/riacho do vilarejo na Colômbia, onde os corpos são encontrados. 
[Narciso Telles]

Um outro elemento de uso, neste primeiro momento, era um balde com água. Eu realizava uma sequência de ações com o balde, intensificandoas. Esse momento foi importante para compreender as características corporais básicas desse personagem, para depois em um processo contínuo acrescentar ações, pausas, sonoridades. A cada encontro, eu e Guilherme íamos desenhando com mais definição toda a errância com as observações da diretora. Com esse material levantado, passamos a trabalhar a Errância III. Nesta fase nos perguntávamos: quais os procedimentos técnicos que visam ao ator 'dar presença ao que não é da ordem da presença'? Como encontrar os limites éticos na representação? Essas questões levaram-me a optar por uma atuação mais performativa, na ação crua da leitura do texto. Leio a partir do meu estado psicofísico no momento do acontecimento junto aos espectadores. Me lanço ao abismo, ao risco inerente e iminente da atuação. Um pacto ético com os espectadores, no qual a representação estabelece um campo relacional com as vozes socias dos familiares dos desaparecidos. Encontro na Errância III a possibilidade do encontro com esses mortos colocando-me também diante da morte do próprio teatro em sua efemeridade, na necessidade de falar desse tema e dar voz aos que em uma outra realidade, procuram seus cadáveres.

\section{[Dirce Helena]}

O processo de criação é, antes de tudo, aquilo que me move, independente, de estar fazendo uma montagem no mercado profissional, ou de estar em um coletivo experimental como o Núcleo 2, ou ainda, de estar trabalhando com a formação de alunos no Curso de Teatro da Universidade Federal de Uberlândia. Para mim, o teatro é processual, e talvez por isso, tenha vindo para UFU, porque na universidade temos a oportunidade de eleger o processual como objeto de pesquisa. Lançar o meu olhar para o processo das errâncias é poder compreender o trajeto da criação e poder entender as questões éticas e estéticas encalçadas no decorrer do trabalho. 
As minhas motivações na direção sempre vêm dos atores, quase sempre eles me apresentam o projeto trazendo os seus desejos, inquietações... Como fazedora de teatro acredito que um coletivo/elenco se faz a partir de algumas exigências, quais sejam, as motivações dos atores, o compromisso com o trabalho e o tema a ser investigado. São estes requisitos fundamentais para a minha integração a um coletivo.

\author{
18 de maio de $2020^{8}$ \\ Infectados no globo terrestre: 4.730 .968 \\ Mortes: 315.488 \\ Brasil em curva ascendente \\ Pessoas infectadas: 241.080 \\ Mortes no país: 16.122
}

\title{
Reprodução do áudio 1 - Continuação
}

Tempos de Errância traz em seu escopo a questão do desaparecimento de corpos, e, neste momento de pandemia, não posso deixar de traçar um paralelo com o que está ocorrendo, obviamente em proporções diferentes, uma vez que o tema das errâncias trata de corpos desaparecidos na América Latina que não tiveram o ritual de passagem junto aos seus familiares. Tal situação, em proporções distintas, está ocorrendo com os corpos das pessoas que morrem na pandemia da COVID-19. Porque também há uma desaparição de corpos nesta pandemia, muitas vezes são enterrados sem a presença de seus familiares... Não há o ritual de passagem. Como resgatar o ritual da morte? Para mim esta é uma questão muito forte, e o coletivo das errâncias terá que repensar a questão do desaparecimento de corpos que está ocorrendo com a pandemia. Embora estejamos vivendo uma catástrofe, acredito e quero acreditar que terá um fim, e a pergunta que não se cala: como falar do desaparecimento de corpos, tema das errâncias, no pós-pandemia COVID-19? Como apresentaremos um espetáculo cujo tema fala sobre a desaparição de corpos com a experiência em que estamos vivendo? Não seremos os mesmos de antes. Isto é um fato. Estaremos diante de novos modos de vida e, possivelmente de novos modos do fazer teatral.

A mobilização de uma direção que os colocasse em ação na improvisação com fragmentos do texto diretamente na área de jogo incorporando as situações apresentadas pelo texto, buscando estabelecer relações com os demais elementos da criação teatral. Trata-se, pois, de uma maneira real de, nas palavras de Ryngaert, "abrir um canteiro de obras em torno de um texto, fazendo-o ser escutado rapidamente junto com elementos de jogo" (RYNGAERT, 2009, p.185).

\footnotetext{
8 Informações extraídas do site: https://coronavirus.jhu.edu/map.html. Acesso em 18 de maio de 2020.
} 


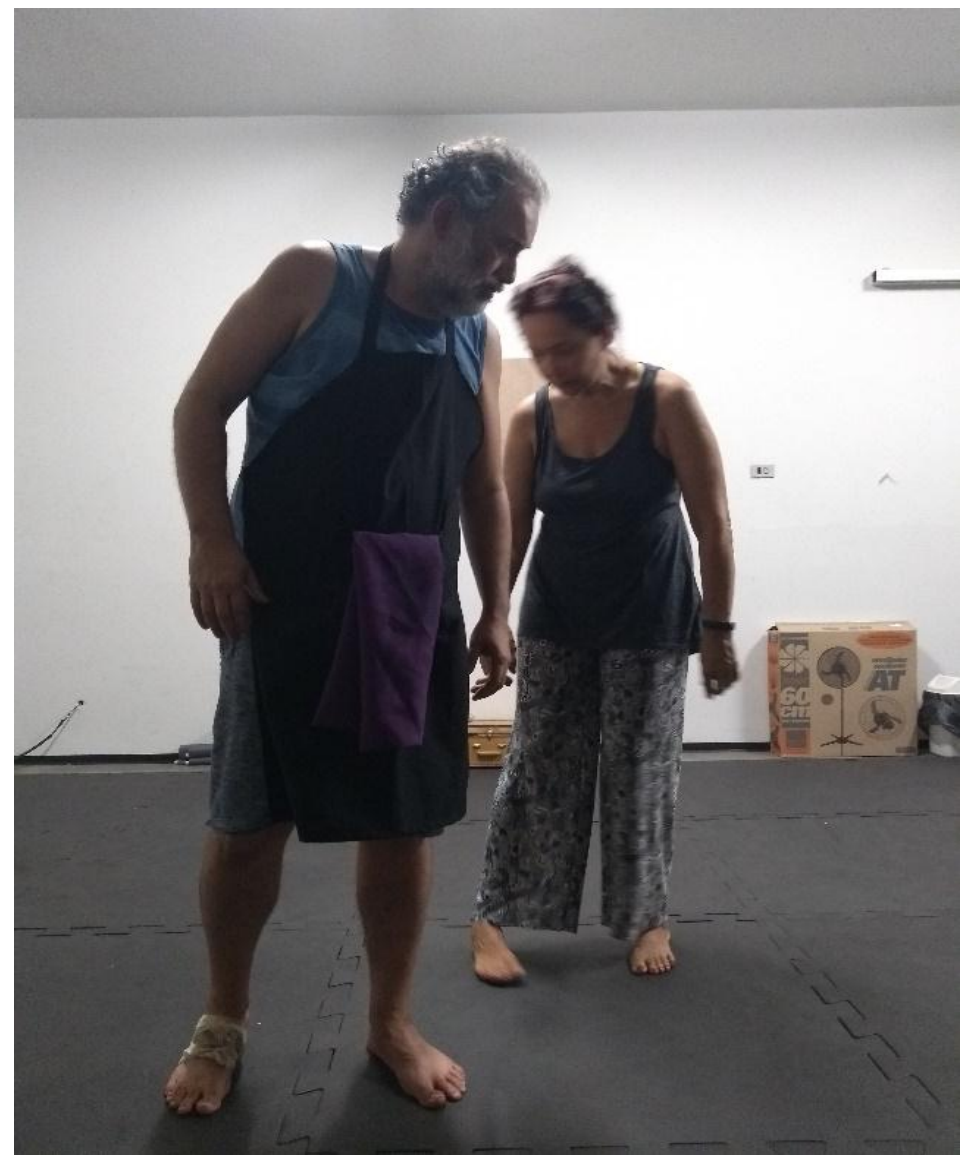

Narciso Telles e Dirce Helena Carvalho Foto do acervo: Karina Silva(@Kaasoli) Local: Sala do CAJÀ/GEAC/UFU

A atuação contemporânea inscreve uma diversidade de possibilidades que abrem perspectivas que fundamentalmente devem ser conduzidas diretamente no espaço de jogo, em proposições que suscitem a participação dos atores a partir da escuta, da observação e da inventividade.

Do mesmo modo, a abordagem do discurso teatral exigiu a intensidade performática dos atores buscando revelar o que estava oculto por detrás das palavras em um tradutibilidade em que o ator-personagemtestemunha deixa-se transitar no espaço de ficção e no espaço da vida real.

[Maria Marques]

Após assistir ao espetáculo Errância e posteriormente, ler o capítulo do livro de Jorge Dubatti - O teatro dos mortos, em especial, o capítulo $O$ teatro como acontecimento, como vocês previram ou constataram "Um ser do estar-acontecer no mundo.", frase que diferencia uma teoria do teatro de uma 
teoria filosófica para o teatro. (aqui, gostaria que vocês comentassem, caso tenham material, do ponto de vista da recepção também). Ainda na perspectiva apresentada por Jorge Dubatti, no mesmo capítulo, estava lendo a passagem na qual o teatro pode ser pensado como ente fundante, metafísico $e$ independente, condição de possibilidade do restante: a vida. Nessa passagem marquei ao lado da página 'Para análise de peça Errância”, apesar de eu ter construido imagens sobre a morte ou um devir dela... não construí uma narrativa, mas quadros em esfumato: um homem que luta com certas condições precárias e violentas, cuja situação leva-o a esperar, conviver e afligir-se constantemente com desaparecimentos de pessoas $e$, posteriormente, o aparecimento de muitos, muitos mortos. Por isso pensei na ideia do teatro como ente fundante, uma condição de possibilidade do restante: a vida.]

[Narciso Telles]

As ausências ou as presenças em memória aparecem com mais força na Errância II no que permanece, as roupas e os sapatos. Nesta a pergunta disparadora foi: como dar presença às ausências? As obras surgidas a partir das teatralidades da dor, termo cunhado por Ileana Dieguez, sempre encontram nessa questão uma potência criativa. A opção que escolhemos foi 'dar vida' às roupas, contar suas histórias. Inventamos essa errância cruzando as vozes/narrativas com técnicas de teatro de animação, atuamos como atores-manipuladores aparentes e em certo sentido cumplices dessas histórias. Na sala de trabalho com as roupas dispersas no chão e a orientação técnica em teatro de animação de Mario Piragibe fomos tecendo suas trajetórias, encontrando-as em relação aos nossos corpos. No processo técnico-inventivo, fomos apurando as dinâmicas, os modos de operação de cada roupa e compreendendo em experiência qual a história escondida em cada uma delas que iam se revelando a cada ensaio. Eduardo Pavlovsky, dizia que atuar é um modo de viver nossa condição humana em um ato extremo. Me percebo no espetáculo nessa condição diferentemente em cada 
uma das três errâncias, para ao fim recolher meus cadáveres e viver a existência.

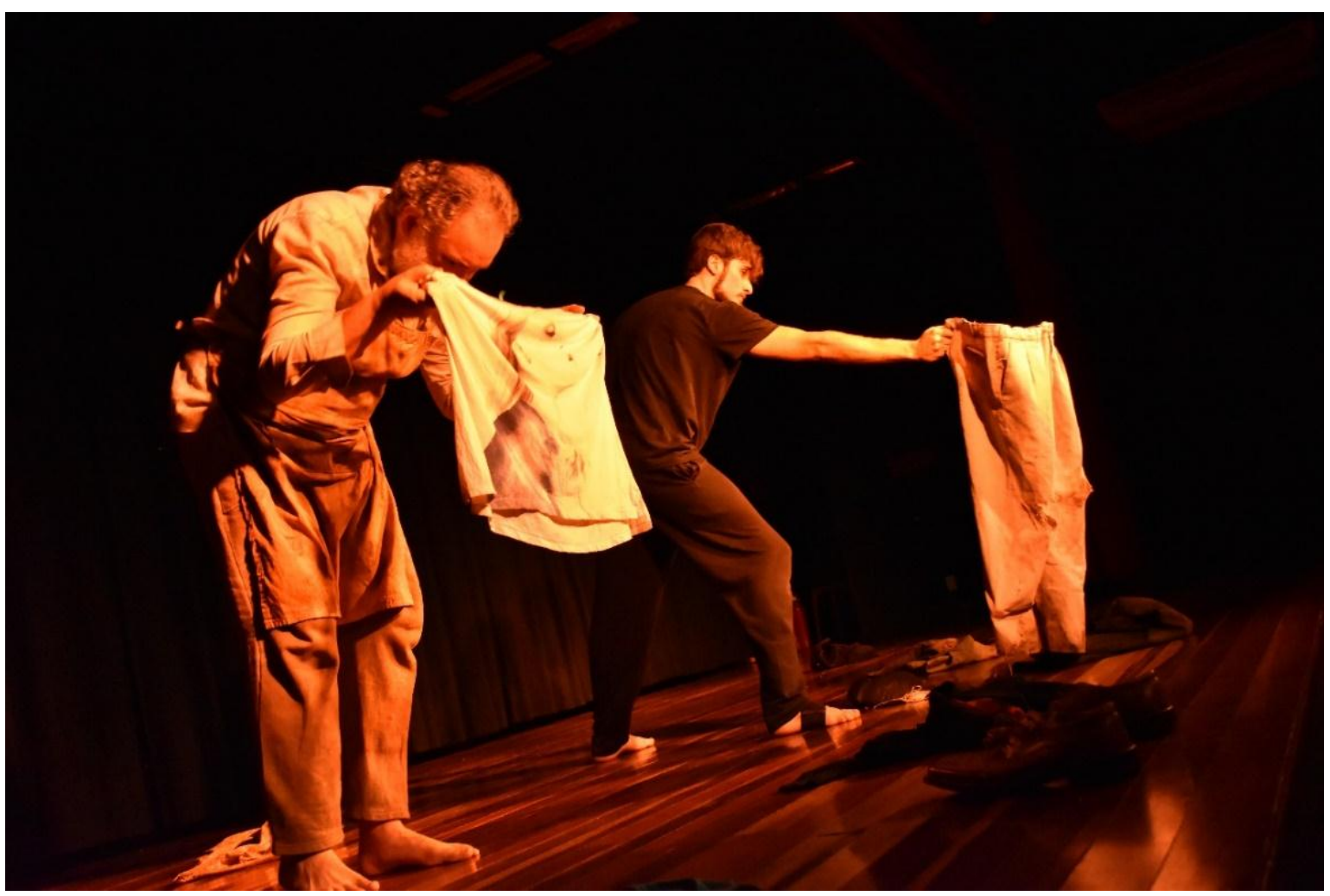

Narciso Telles e Guilherme Conrado

Local: Teatro Shopping Park - Uberlândia - MG

Foto do acervo: Polly Rosa (@pollyrosa1871)

Por fim, cremos que, como Artaud, tenhamos que pensar o que nos mobiliza para criar uma obra em torno da morte.

Não podemos viver eternamente rodeados de mortos e de morte.

E se ainda restam preconceitos devem ser destruídos 'dever'

Digo bem O DEVER

Do escritor, do poeta não é ir fechar-se covardemente num texto, um livro,

Uma revista dos quais jamais sairá.

Senão ao contrário sair à rua para sacudir

Para atacar o espírito público se não para que serve?

E para que nasceu? (ARTAUD, Cavalo Louco, p. 44, 2008).

Com Tempos de Errância, removamos esse manifesto de Artaud ocupando os espaços cênicos como um rito poético que ora, grita e ora se manifesta, em nossos corpos, as ausências presentes. 


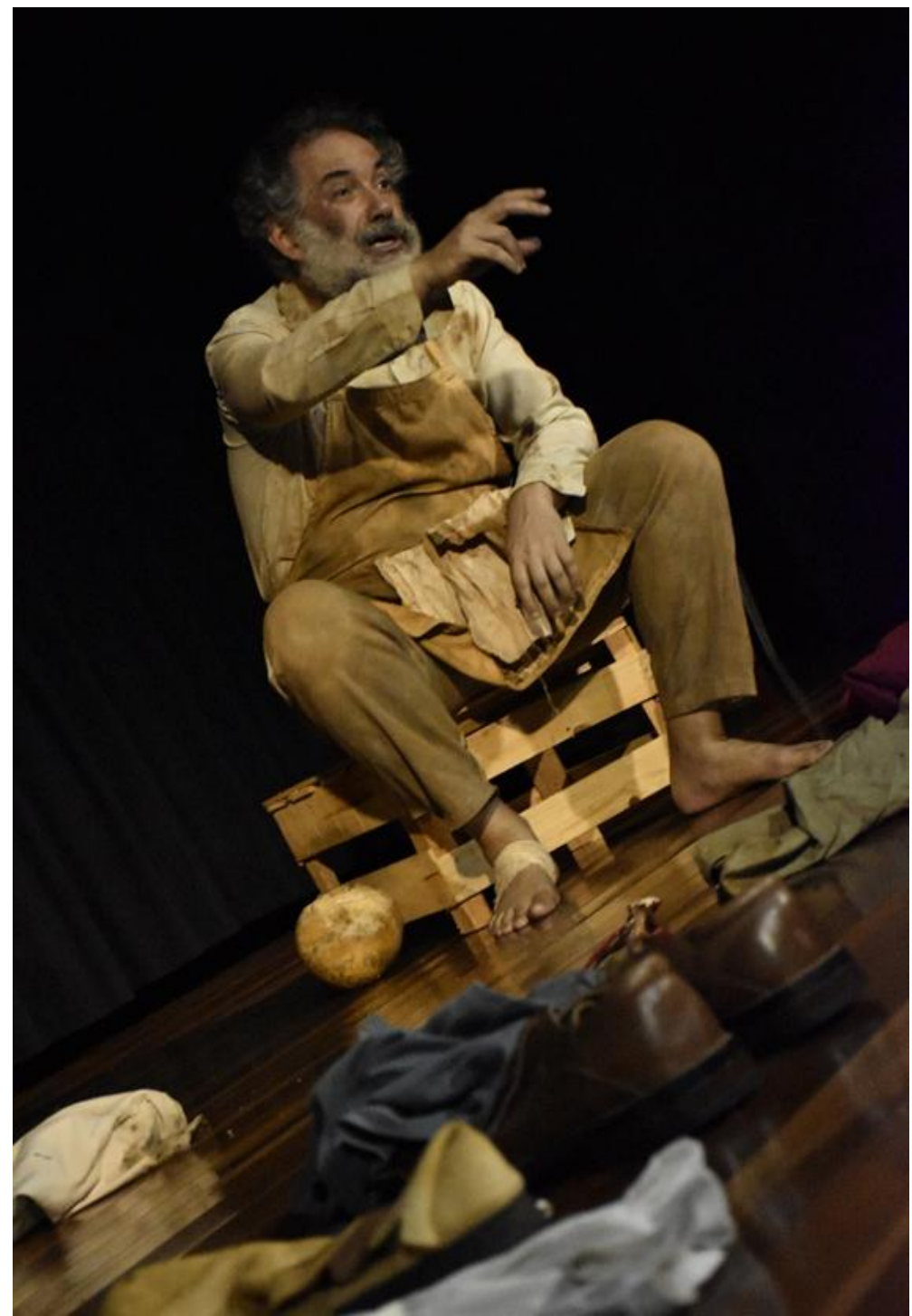

Atuação de Narciso Telles. Tempos de Errância Local: Teatro Shopping Park - Uberlândia -MG Foto do acervo: Polly Rosa (@pollyrosa1871)

[Dirce Helena]

Acreditamos na necessidade da arte que possibilita perpetuar a história da humanidade, certificando-nos que o teatro é um modo de viver e, neste momento pandêmico urge, de nós artistas, clamarmos pelas ausências presentes, corroborando com o que já foi preconizado pelo arauto do teatro, Antonin Artaud.

E, por fim, reproduzindo os dados do Ministério da Saúde no dia 22 de junho de 2020, com oito milhões novecentos sessenta e nove mil e oitocentos e vinte e sete infectados, perfazendo um total de quatrocentas e sessenta e oito mil e quinhentas e oitenta e nove morte, quinhentos e oitenta 
e nove mortes e no Brasil continuamos em curva ascendente, com um milhão oitenta e três mil e trezentas e quarenta e uma pessoas infectadas totalizando cinquenta mil, quinhentas e noventa e uma mortes.

22 de junho de $2020^{9}$.

Infectados no globo terrestre: 8.969 .827

Mortes: 468.589

Brasil em curva ascendente

Pessoas infectadas: 1.083 .341

Mortes no país: 50.591

$* * *$

\section{REFERÊNCIAS}

ARTAUD, Antonin. Poema sem título. Cavalo Louco. Revista da Tribo de Atuadores Ói Nóis Aqui Traveiz, n. 04, março de 2008, p. 44.

Catálogo de exposição: GOYA DIBUJOS: Solo la voluntad me sobra. Museu Nacional do Prado. Madri, 20 de novembro de 2019 a 16 de fevereiro de 2020 .

DIÉGUEZ, Ileana. Os corpos em soberania 'totalitária'. In: TOURINHO, Lígia.

MITKIEWICZ, Luciana (orgs). Bonecas Quebradas. Ensaio de um processo criativo em teatro documental. Rio de Janeiro: Azougue, 2016. p. $20-41$.

DUBATTI, Jorge. Teatro dos Mortos: uma introdução à filosofia teatral. São Paulo: Editora Sesc, 2016.

NANCY, Jean Luc. Corpus. Madrid: Arena Libros, 2003.

${ }_{9}^{9}$ Dados extraídos do site: https://coronavirus.jhu.edu/map.html. Acesso em 22 de junho de 2020 . 
PAVLOVSKY, Eduardo. Resistir Cholo: cultura y politica en el capitalismo. Buenos Aires: Topía Editorial, 2015. [Livro digital PDF]. RYNGAERT, Jean Pierre. Jogar, representar: práticas dramáticas e formação. São Paulo: Cosac Naify, 2009.

SANCHEZ, José Antônio. Ética de la representación. Apuntes de Teatro. Santiago do Chile, 2016, n. 138, p. 9-25. Disponível em https://blog.uclm.es/ joseasanchez/2014/07/14/etica-de-la-representacion-2014. Acesso em 18/06/ 2020.

SARRAZAC, Jean-Pierre. A invenção da teatralidade. Sala Preta (ECA/USP), v. 13, nº , São Paulo, p.56-70, 2013. Disponível em: http://www. revistas.usp.br/salapreta/rt/printerFriendly/57531/68222. Acesso em 29 de maio de 2020.

Recebido em agosto de 2020. Aprovado em setembro de 2020.

Publicado em outubro de 2020. 